Look before you leap: Visual navigation and terrestrial locomotion of the intertidal killifish Fundulus heteroclitus

\author{
Honors Thesis \\ Presented to the College of Arts and Scienes \\ Cornell University \\ in Partial Fulfillment of the Requirements for the \\ Biological Sciences Honors Program
}

by

Noah Bressman

May 2016

Supervisor Dr. William Bemis 


\title{
Look Before You Leap: Visual Navigation and Terrestrial Locomotion of the Intertidal Killifish Fundulus heteroclitus
}

\author{
NOAH R. BRESSMAN ${ }^{1 *}$, \\ STACY C. FARINA ${ }^{1}$, AND ALICE C. GIBB ${ }^{2}$ \\ ${ }^{1}$ Cornell University, Ithaca, New York \\ ${ }^{2}$ Northern Arizona University, Flagstaff, Arizona
}

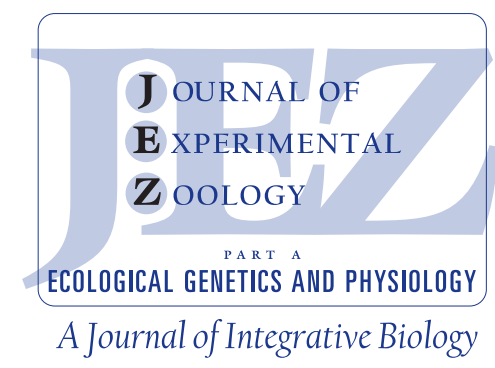

\begin{tabular}{|c|c|}
\hline ABSTRACT & $\begin{array}{l}\text { Mummichogs (Fundulus heteroclitus; Cyprinodontiformes) are intertidal killifish that can breathe } \\
\text { air and locomote on land. Our goals were to characterize the terrestrial locomotion of } \\
\text { mummichogs and determine their method of navigation towards water in a terrestrial } \\
\text { environment. We used high-speed video to record behavior during stranding experiments and } \\
\text { found that mummichogs use a tail-flip jump to move overland, similarly to other } \\
\text { Cyprinodontiformes. However, mummichogs also prop themselves upright into a prone position } \\
\text { between each jump, a previously undescribed behavior. After becoming prone, mummichogs rotate } \\
\text { about their vertical axis, directing the caudal fin towards the water. Then, they roll back onto their } \\
\text { lateral aspect and use a tail-flip behavior to leap into a caudally-directed, ballistic flight path. We } \\
\text { conducted experiments to determine the sensory stimulus used to locate a body of water by } \\
\text { placing mummichogs on a square platform with one side adjacent to a sea table. Under artificial } \\
\text { light, mummichogs moved towards the sea table with a higher frequency than towards the other } \\
\text { sides. Under dark conditions, mummichogs did not show a preference for moving towards the sea } \\
\text { table. When the surface of the water was covered with reflective foil, mummichogs moved towards } \\
\text { it as if it were a body of water. These results suggest that mummichogs primarily use visual cues, } \\
\text { specifically reflected light, to orient towards the water. The uprighting behavior that mummichogs } \\
\text { perform between terrestrial jumps may provide an opportunity for these fish to receive visual } \\
\text { information that allows them to safely return to the water. J. Exp. Zool. 325A:57-64, 2016. } \odot 2015 \\
\text { Wiley Periodicals, Inc. }\end{array}$ \\
\hline & $\begin{array}{l}\text { w to cite this article: Bressman NR, Farina S, Gibb A. 2016. Look before you leap: Visual } \\
\text { vigation and terrestrial locomotion of the intertidal killifish Fundulus heteroclitus. J. Exp. } \\
\text { ol. } 325 \mathrm{~A}: 57-64 \text {. }\end{array}$ \\
\hline
\end{tabular}

The intertidal zone is a dynamic habitat, immersed in water during high tide and exposed to the air during low tide. When the tide recedes, tidepools may lose their connection with the ocean, isolating intertidal fishes in these pools. Because these pools are stagnant and often exposed to intense sunlight, they can quickly become hypoxic, develop high concentrations of salt and waste, or dry up completely; all of these conditions will create a physiologically challenging environment for fishes (Martin and Bridges, '99; Taylor et al., 2008). Because tidepools may disappear or become inhospitable, many intertidal fishes display adaptations for surviving brief periods out of water, including the ability to navigate between bodies of water (Mast, '15; Goodyear, '70;
Grant sponsor: Andrew W. Mellon Foundation; grant sponsor: National Science Foundation; grant number: DEB-1310812.

Additional supporting information may be found in the online version of this article at the publisher's web-site.

${ }^{*}$ Correspondence to: Noah Ryan Bressman, 11 Pine Cliff Road, Chappaqua, NY, 10514. E-mail: nrb66@cornell.edu

Received 3 July 2015; Revised 15 October 2015; Accepted 15 October 2015

DOI: $10.1002 /$ jez.1996

Published online 5 November 2015 in Wiley Online Library (wileyonlinelibrary.com). 
Aronson, '71), locomote on land (Gibb et al., 2011; King et al., 2011; Gibb et al., 2013), and extract oxygen from the air (Hughes and Singh, '70; Gervais and Tufts, '98; Martin and Bridges, '99; Ong et al., 2007). These adaptations make intertidal fishes ideal subjects for experiments that investigate behavioral, sensory, and locomotor strategies for surviving on land.

The mummichog (Fundulus heteroclitus) is a widespread species of killifish (Cyprinidontiformes) that is commonly found in intertidal habitats, including marshes, sandbars, and rocky tidepools along the Atlantic coast of North America, from Nova Scotia to Georgia (Martin and Bridges, '99). Many killifishes that live at the water's edge in ponds, streams, or in the intertidal, exhibit amphibious adaptations. For example, mummichogs and the mangrove rivulus (Kryptolebias marmoratus) can extract oxygen from the air using their gills and skin (Halpin and Martin, '99; Martin and Bridges, '99; Ong et al., 2007). The mangrove rivulus can survive on land for weeks at a time in a moist environment (Ong et al., 2007; Taylor et al., 2008). In addition, killifishes and livebearing cyprinodontiform fishes (e.g., Gambusia affinis) can perform terrestrial jumps (Gibb et al., 2011; Mast, '15) and will use jumping and other behaviors to move over land from one body of water to another (Mast, '15; Goodyear, '70).

Locomotion on land is challenging for fishes, at least in part because they lack the ability to lift their center of mass off the ground using two sets of paired limbs (Gibb et al., 2013). Instead, many ray-finned fishes employ ballistic behaviors in which they launch their center of mass into the air (Gibb et al., 2013). One apparently widespread terrestrial behavior is the tail-flip jump, during which high-curvature bending of the body away from the substrate is followed by contralateral flexion of the posterior body, which pushes the caudal peduncle against the ground to launch the fish into a ballistic trajectory (Gibb et al., 2011; Gibb et al., 2013; Boumis et al., 2014). The tail-flip jump allows a fish to move overland, even if an incline is not present. However, another type of ballistic behavior is seen in mudskippers and other fishes that frequently emerge from water: prone jumping. Prone jumpers, such as mudskippers (Periopthalmus spp.) and Pacific leaping blennies (e.g., Alticus arnoldorum), move from an upright position, in which their ventral surface rests on the substrate (Swanson and Gibb, 2004; Hsieh, 2010; Gibb et al., 2013); this orientation has been proposed to improve a fish's ability to acquire sensory information while on land by allowing it to observe the environment from an upright position (Gibb et al., 2013). Sitting in an upright position will elevate a fish's eyes above the ground and improve their visual field, thus allowing them to better search for prey, predators, conspecifics, or water.

When in water, fishes navigate through their habitats using a combination of vision (Hawryshyn, '92), mechanoreception (the vestibular system, the lateral line, and hearing; Webb et al., 2008), and olfaction (Hara, '75). However, when fishes are on land, the change in the physics of their environment likely impacts their sensory capabilities, and little is known about how fishes are able to navigate a terrestrial environment. It seems unlikely that fishes can use their lateral line system when on land, as this system relies on near-field fluid movements, and the spatial extent of the near field is greatly reduced in air when compared with water (Harris and van Bergeijk, '62; Coombs and Montgomery, '99). Some cyprinodontiform fishes, like Gambusia affinis, use the otolith-vestibular system to obtain sensory information on land (Boumis et al., 2014), but this system can only provide information about body position; it is unlikely that the otolithvestibular system can aid in locating a body of water when the fish is positioned on flat ground. In some situations, fishes may use their vision to detect celestial cues when navigating toward water: a study by Goodyear ('70) found that Fundulus notti were able to use the sun as a compass to return to the water. Because the refractive properties of water and air are very different, it is unlikely that mummichogs (Fundulus heteroclitus) can focus well enough in air to distinguish physical landmarks in their environment. However, some animals, such as beetles, follow the reflection of light off surfaces to locate water sources (Szentkirályi et al., 2003). We hypothesize that, in the absence of celestial cues, mummichogs navigate across land by searching for light reflecting off the surface of water.

Because mummichogs are found in pools throughout the intertidal zone and may often become stranded, they represent an intermediate modality between fishes that frequently leave the water voluntarily (e.g., K. marmoratus and Periopthalmus spp.) and fishes that are fully-aquatic and never voluntarily leave the water. Therefore, the overarching objective of this study is to answer the question: "how do mummichogs navigate their environment to return to the water?" From this question, we developed three specific goals: (1) to characterize the terrestrial locomotion of mummichogs, including describing non-propulsory behaviors that may be used to aid the fish in gathering sensory information, (2) to assess the success of mummichogs in locating a body of water under controlled conditions, and (3) to determine the importance of vision in the terrestrial navigation of mummichogs and identify the cues associated with visual navigation.

\section{MATERIALS AND METHODS}

On July 31st, 2013, we used minnow traps to collect 30 mummichogs (ranging from 3 to $6 \mathrm{~cm}$ in total length (TL; as defined as the length from the tip of the snout to the end of the caudal fin) and 2-6g in mass) from tidepools on Appledore Island at Shoals Marine Lab (SML) in the Gulf of Maine. Fish were held in a sea table with flowing seawater pumped from the surface of the waters around the marine station for $48 \mathrm{hr}$ before the experiments were conducted. These individuals were used for a preliminary navigation experiment to assess whether mummichogs can successfully navigate towards a body of water in an unfamiliar terrestrial environment. An indoor platform $(80 \times 80 \mathrm{~cm})$ covered with smooth, dry plastic sheeting was placed next to a seawater 
table at the same height as the lip of the table (to create a terrestrial surface directly adjacent to the water for the experiment), such that only one side of the square platform allowed access to the water in the sea table. Buckets were placed below the platform to catch any fish that left the platform away from the sea table. The mummichogs were individually placed on the platform and allowed to move freely for a period of up to 5 min, during which time their paths were manually tracked. To track the fish, a grid was created on the platform and a scaled grid was drawn in a lab notebook; during the trials, the position of each fish after each jump was recorded on the grid in the notebook. The same observer conducted all experiments in this study. To analyze the directionality of the jumps, we transferred all of the trajectories from the lab notebook onto a digital image of a single square grid for each fish that reached the edged of the platform. We used ImageJ (Schneider et al., 2012) to analyze the grid and determine the angular direction of the final jump for each fish. The direction of the sea table (using the midpoint of the side of the platform with access to the water) was chosen as zero degrees and each angle of final jump direction was measured relative to zero $\left(360^{\circ}\right.$ total). We used the CircStats package (Lund and Agostinelli, 2012) in R (version 3.0.2; R Core Team, 2013) to visualize the distribution of angles (circ.plot and rose.diag functions) and to perform a Rayleigh's test of uniformity ( $v 0 . t e s t$ function), specifying a mean direction of 0 degrees as the alternative to the null hypothesis that there was no mean direction of the fish.

In late July of 2014, we collected 150 additional mummichogs (ranging from 3 to $6 \mathrm{~cm}$ in TL and 1.3-6 g in mass) using the same methods and from the same locations as in 2013. These fish were acclimated to laboratory conditions for 1 week before the start of experimentation. During acclimation, the fish were kept in an indoor, flow-through aquarium with natural lighting from windows and air and water temperatures similar to the outdoors. We fed the fish every other day a diet of algae, clams, and dead mackerel (purchased as bait). We placed a wooden platform with a square grid on top of a seawater table so that only one side of the grid was adjacent to water (Fig. 1). During this set of experiments, 30 mummichogs were randomly chosen and individually placed on the platform for observation. The platform was moistened with seawater but was not covered with plastic sheeting in this set of experiments. The fish were allowed to move freely during the experimental trials. During these trials, behaviors were recorded from a lateral view $\left(0^{\circ}\right.$ angle, relative to the surface of the platform) or an overhead view (which ranged from approximately $50-70^{\circ}$ angle relative to the platform surface) with a Casio Exilim FH-20 High Speed Camera (recording digital images at 210 FPS). Locomotor kinematics were analyzed by using ImageJ to examine the videos frame-by-frame.

Using the same platform as used for the behavioral observations, we also performed a navigational experiment with three treatments: light, dark, and foil (see descriptions

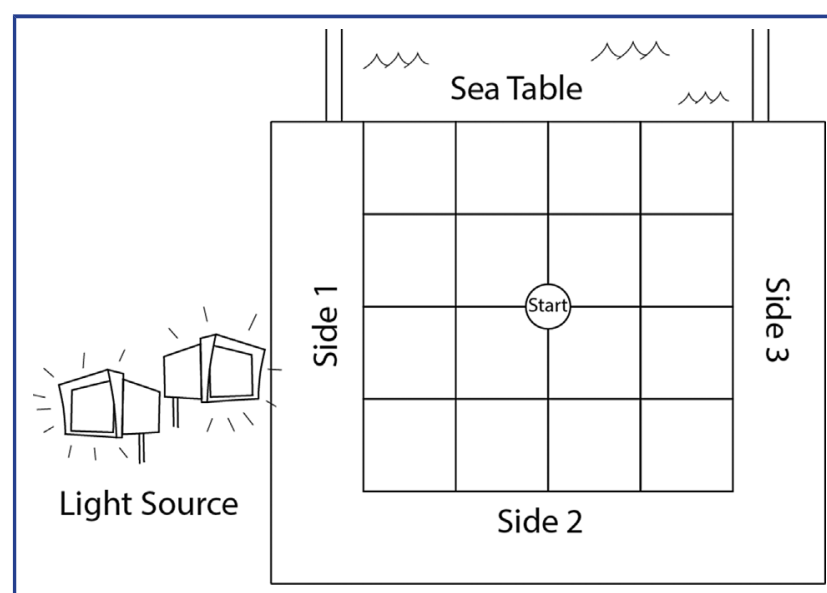

Figure 1. Stranding trials for Fundulus heteroclitus were conducted on a square experimental platform that provided access to the water on one side. Fish were deployed on a smooth, moist, wooden platform that was marked with a grid. Each square of the grid on the experimental platform had dimensions $2.54 \mathrm{~cm}$ by $2.54 \mathrm{~cm}$. Three sides of the platform did not allow the fish to return to the water (Side 1, Side 2, and Side 3); the fourth side (Side 4) directly abutted a sea table containing water.

below). Data for these experiments were collected between 8:00 $\mathrm{pm}$ to 12:00 am to control for potential differences in behavior based on time of day and all windows were blocked using black cloth to eliminate ambient light cues. For each treatment, mummichogs were individually placed in the center of the moistened platform (sampling without replacement) and were allowed to move freely for up to $5 \mathrm{~min}$, or until they left the platform. Individuals that failed to leave the platform altogether $\left(\mathrm{n}_{\text {light }}=14, \mathrm{n}_{\text {dark }}=8, \mathrm{n}_{\text {foil }}=10\right)$ were not included in the statistical analysis. Observations of the direction of jumps, timing of jumps, and final destination were made from video recordings ( $30 \mathrm{fps}$ ) for the light and foil treatments and by visual observation for the dark treatment (following the protocol of recording jump trajectories to a lab notebook, as described above) because insufficient light was available for recording videos. All animal care and experimentation followed Cornell University IACUC protocol 2013-0017.

For the "light" treatment $(\mathrm{n}=51)$, light was distributed evenly around the experimental platform by using halogen floodlamps pointed directly at the ceiling above the platform from Side 1 (Fig. 1). The purpose of the light treatment was to determine whether mummichogs could successfully navigate from an unfamiliar body of land to the nearest unfamiliar body of water, and it also served as a positive control for the two additional treatments. For the "dark" treatment $(n=27)$, conditions were the same as those of the light treatment, except that the light in the laboratory was reduced to a level at which the outline of the fish 
could just barely be seen by the observer. The purpose of this treatment was to test whether vision was important in the terrestrial navigation of mummichogs by experimentally reducing their ability to receive visual information. For the "foil" treatment $(n=23)$, conditions were the same as used in the light trials, except that manually creased aluminum foil was placed over the water to mimic the reflective nature of the water's surface. The purpose of the foil treatment was to test the hypothesis that reflected light is the major attribute of water that attracts mummichogs. For all experimental treatments, different individuals were used, and each fish was only used for a single experiment.

To analyze each treatment, we used a $\chi^{2}$ goodness of fit test to assess whether individuals that left the platform did so via the side with sea table access more frequently than expected due to chance. Because the experimental area of the platform was square, in each of the trials, there was a $25 \%$ probability that an individual would jump off each of the four sides of the platform due to chance alone. Therefore, our expected frequency for fish leaving each side of the platform was $25 \%$ of the total number of individuals. We used the chisq.test function of the standard statistics package in $R$ (R Core Team, 2013) to calculate the $\chi^{2}$ test statistic, $\mathrm{p}$-value, and standardized Pearson residuals (Table 1) for each treatment. Two-proportion Z-tests were also used to compare the number of fish that went to the water in dark and foil treatments, relative to the light treatment. For the light trial, jumping frequency (jumps per minute) was calculated for two categories: fish that moved towards the water and fish that moved to one of the other three sides of the platform. The mean jumps per minute for these two categories were compared using a twosample t-test to determine whether mummichogs jump more frequently when they are headed towards water.

Table 1. Comparison of residuals for the frequencies of individuals leaving each side of the experimental platform in each treatment.

\begin{tabular}{|c|c|c|c|c|}
\hline & Side 1 & Side 2 & Side 3 & $\begin{array}{c}\text { Sea table or } \\
\text { foil }\end{array}$ \\
\hline \multicolumn{5}{|l|}{ Light } \\
\hline Observed ${ }^{1}$ & 13 & 1 & 4 & 19 \\
\hline Residuals $^{2}$ & 1.42 & -3.13 & -1.99 & 3.70 \\
\hline \multicolumn{5}{|l|}{ Dark } \\
\hline Observed $^{1}$ & 4 & 7 & 6 & 3 \\
\hline Residuals $^{2}$ & -0.52 & 1.03 & 0.52 & -1.03 \\
\hline \multicolumn{5}{|l|}{ Foil } \\
\hline Observed $^{1}$ & 4 & 0 & 1 & 8 \\
\hline Residuals $^{2}$ & 0.48 & -2.08 & -1.44 & 3.04 \\
\hline
\end{tabular}

\section{RESULTS}

When stranded in the center of a flat surface in the laboratory with a sea table on one end (approximately $40 \mathrm{~cm}$ away), mummichogs would wriggle and jump to move around the surface, typically resting in an upright (anatomically prone) position when they were not actively moving (Fig. 2; Supplementary S-Video 1). A wriggle behavior is defined here as yawing (rotating around the vertical axis of the body) to orient the tail in the intended direction of travel; this movement appeared to be driven by asymmetric lateral movements of the tail. To move long distances, mummichogs produced jumps by rolling over on their lateral side, bending their heads towards their tails, then pushing off with their peduncle in a caudally-oriented jump (S-Video 1); this behavior is consistent with previously described tail-flip jumps in other small actinopterygian (ray-finned) fishes (Gibb et al., 2011, 2013). Mummichogs (TL $=4-6 \mathrm{~cm}$ ) produced jumps of up to $10 \mathrm{~cm}$ ( $>2$ body lengths (BL), as measured using total length) vertically (above the platform), and over $20 \mathrm{~cm}$ (>4 BL) in a horizontal direction. At the end of the flight phase of the jump, a mummichog would typically land on its side (lateral aspect), but then quickly reorient into a prone (upright) posture.

In between consecutive jumps, mummichogs consistently (95\% of the time, see below) reorient into an upright posture (Fig. 2). To adopt an upright position while starting from its lateral side, a mummichog pushes off the ground with one pectoral fin (the one in direct contact with the ground), while simultaneously curling its head towards its tail (S-Video 1), or by performing a small "thrash" (a movement in which the body flexes toward the substrate, as defined by Gibb et al., 2013). Less frequently, mummichogs perform a small tail-flip jump and land in an upright body orientation. Once in an upright position, a fish rests on its ventral surface, with a slight curve along the body. The mummichogs adopted an upright position 95.2\% $(n=49)$ of the time during the interval between two consecutive jumps. Using a subset of jumps where fish could be seen to perform reorientation

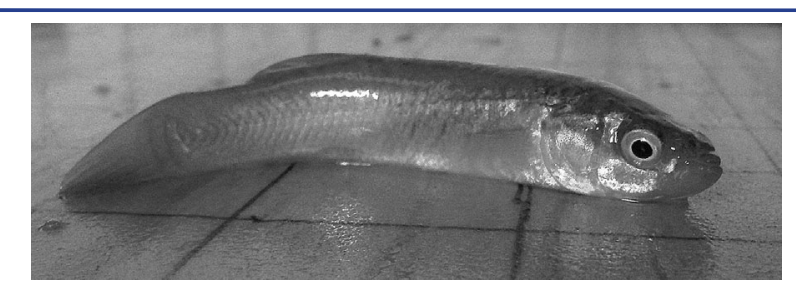

Figure 2. Fundulus heteroclitus adopt an upright position between terrestrial jumps across an experimental platform. Between each jump, individuals of $F$. heteroclitus typically return to an upright position (shown here), sometimes for only a fraction of a second. Each square of the grid marked on the platform had dimensions $2.54 \mathrm{~cm}$ by $2.54 \mathrm{~cm}$. 
behaviors at angles favorable to the camera $(n=10)$, the average duration of uprighting maneuvers was determined to be $0.12 \mathrm{sec}$ $(\sigma=0.02)$. Occasionally, a fish would land upright at the end of the jump and would not need to employ any uprighting behaviors. However, in this circumstance, a fish would roll back onto its side to jump again. To roll onto its side, a fish rotates its body about the long axis, towards one side (a move initiated at the head and tail); this maneuver is often accompanied by a lateral movement of the tail. We often observed upright mummichogs wriggling (as defined above) to change their orientation relative to the water before rolling onto their sides and jumping. During wriggling, mummichogs reorient their bodies, but cover little to no distance.

There is a cyclical nature to the terrestrial behavior and locomotion of mummichogs: they perform a tail-flip jump, land on their side, perform a reorientation behavior to bring themselves to an upright position (sometimes they wriggle and reorient the body in a different direction), roll onto their side, and jump again, restarting the cycle. However, individual mummichogs did vary in behavior. Some fish would immediately move towards the water and reach the water within one second, using as few as two jumps. Others would move in an apparently random pattern around the platform before choosing a direction and then moving in a more linear manner. A few fish did not move at all during the 5-min trials; some of these fish produced bubbles with their mouths, eventually covering the anterior half of the body in bubbles.

Of the 30 mummichogs used in our preliminary terrestrial navigation trials, 15 traveled far enough away from the center of the arena to physically leave the platform. Of those 15 fish, eight left the platform at the edge that abutted the sea table and entered the water. This result suggested that mummichogs demonstrate a preference (Fig. 3) for moving towards the water (Rayleigh's test of uniformity, $\mathrm{P}=0.029$ ). The seven fish that did not enter the sea table, yet left the platform, landed in buckets placed under the experimental arena and were immediately transported back to the holding sea table by the observer.

We also compared the response of the mummichogs to different visual stimuli by providing the fish with visual information from the water (light treatment), no visual information from the water (dark treatment), or a non-water reflected light stimulus (foil treatment). During terrestrial trials conducted using conditions that mimicked natural daylight (light), 37 of the 51 fish left the platform. Of these 37 fish, more than half (19) left the platform on the side adjacent to the sea table and landed in the water (Table 1; Fig. 4B); the other 18 left the platform on sides of the table that were not adjacent to the water. Fish moved towards water at rates much greater than would be expected by chance alone $\left(\chi^{2}=22.135 ; \mathrm{P}<0.0001 ; \mathrm{df}=3\right)$. As a post hoc analysis for the $\chi^{2}$ test, we compared standardized Pearson residuals for the observed frequencies of individuals leaving each of the four sides of the platform (Table 1). A high absolute value for a standardized

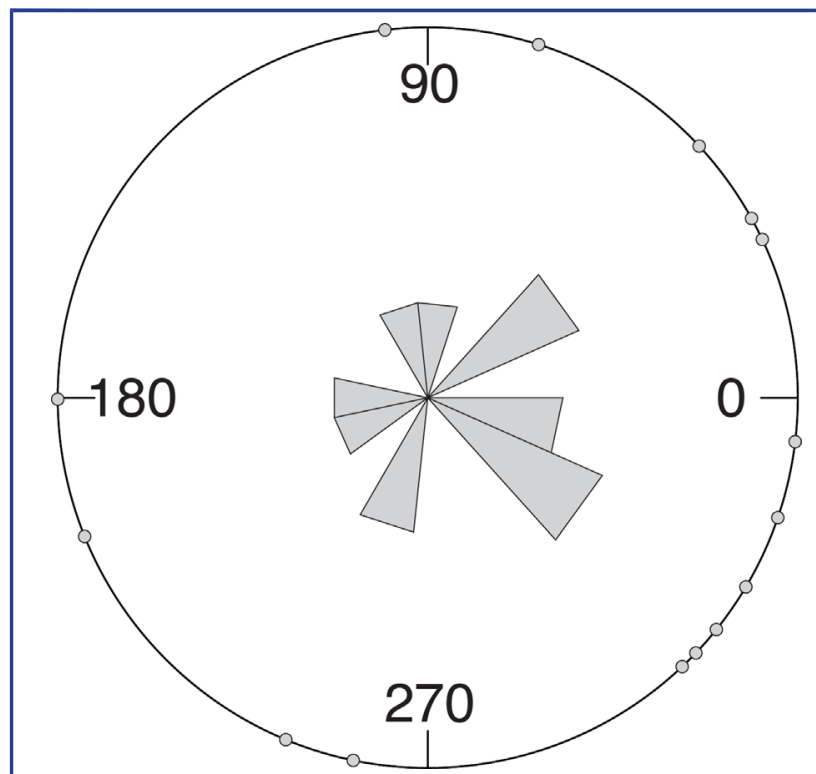

Figure 3. Fundulus heteroclitus demonstrate directionality during jumping trials under light conditions. F. heteroclitus tested during summer 2013 displayed a preference for movement towards the sea table at one end of the experimental platform. The direction of the final jump $\left(^{\circ}\right)$ was calculated for each of the mummichogs $\left(0^{\circ}\right.$ representing movement directly towards the water); F. heteroclitus individuals repeatedly moved towards the water with a frequency greater than chance (Rayleigh's test of uniformity $P=0.029$ ). Gray circles indicate the direction of the final jump for each individual, and cones provide a histogram of these data.

Pearson residual (greater than 2) indicates that a given observation shows a considerable deviation from the expected result (Agresti, 2002). The side with sea table access had high positive residuals, indicating a strong preference for that side. Sides 2 and 3 had high negative values for the residuals (Table 1), indicating that individuals were leaving the platform from those sides infrequently. The residual for side 1 , where our light source was located, was positive but relatively low in value, indicating that it was not substantially different from the frequency expected due to chance.

For this light treatment, the 19 fish that reached the water jumped with an average rate of 27.5 jumps per minute (jpm, $\sigma=44.2)$ to reach the water, while the fish that reached nonwater edges of the platform $(n=18)$ used an average of $15.4 \mathrm{jpm}$ $(\sigma=24.2)$. Some fish that went towards the water jumped at up to $150 \mathrm{jpm}$; however, this did not mean fish performed 150 sequential jumps-rather, they performed a few jumps in very rapid succession to reach the water quickly. Because of this, jump frequency tended to be higher in fish that moved towards the 


\section{A. Expected}

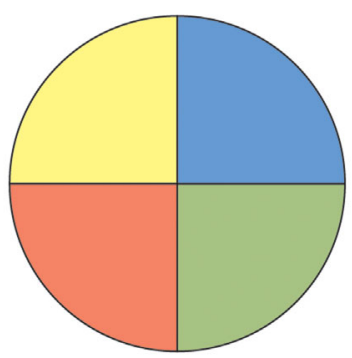

C. Dark Observed
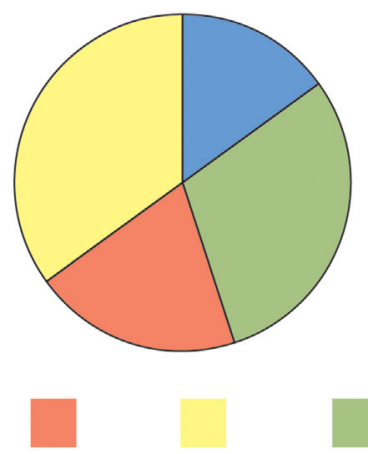

Side 1

\section{B. Light Observed}

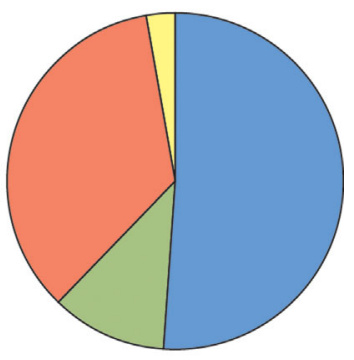

D. Foil Observed
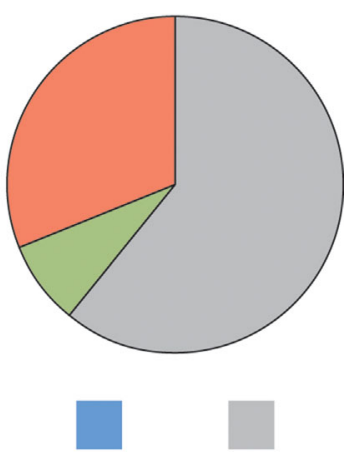

Water
Foil
Figure 4. Reflected light influences the directionality of movement of Fundulus heteroclitus across an experimental platform. The expected pie chart shows the percentages expected from random chance alone. This null hypothesis is based on a square platform, where a fish placed in the center would have a $25 \%$ chance of leaving the platform on any of the four sides. The foil (D) and light (B) Observed results are significantly different from the Expected $(A)(P<0.0001$ and $P=0.008$, respectively), while the dark $(C)$ Observed is not significantly different from the null hypothesis $(P=0.57)$.

water. This trend was not significant due to the high degree of variation among individuals $(\mathrm{t}=1.0 ; \mathrm{P}=0.15 ; \mathrm{df}=28.2)$.

Of the 28 mummichogs tested in dark conditions, 20 fish moved far enough to leave the experimental platform, but only three reached the edge of the sea table and entered into the water (Fig. 4C); this was not different from what would be expected by chance alone $\left(\chi^{2}=2.0 ; P=0.57 ; d f=3\right)$. In the foil experiment, 11 out of 22 mummichogs moved far enough to leave the platform, and eight of those moved from the experimental platform and onto the foil (Fig. 4D); this was significantly greater than chance $\left(\chi^{2}=11.9 ; \mathrm{P}=0.008 ; \mathrm{df}=3\right)$. In addition, $\mathrm{a}$ comparison of the standardized Pearson residuals showed that there was a strong preference for movement towards the foil (Table 1). Using a 2-proportion Z-test, we found a significant difference between the light and dark treatments $(Z=2.7$; $P=0.007)$, while there was no significant difference between the light and foil treatments $(\mathrm{Z}=-0.6 ; \mathrm{P}=0.53)$.

\section{DISCUSSION}

Under light conditions that mimicked daylight, mummichogs (Fundulus heteroclitus) preferentially moved towards the body of water at one end of the experimental arena. Mast ('15) demonstrated that Fundulus majalis have the ability to navigate on land to return to water, but he did not suggest that fish orient toward the reflection of light off the water. While Mast ('15) observed F. majalis successfully navigating from a tidepool, over a sandbar, into the ocean, it was possible that these fish had memorized their habitat during high tide, like the intertidal gobiid species described by Aronson ('71), and used a mental map to navigate to the ocean. However, the mummichogs in this study were able to navigate from an unfamiliar terrestrial environment to an unfamiliar body of water, so it was impossible for them to use a mental map to navigate towards water.

The mummichogs in the light treatment were better able to navigate towards water than the fish in the dark treatment, suggesting that vision is important for the terrestrial navigation in this species. Mummichogs in the dark showed no preference for any direction, suggesting that, in the absence of light, mummichogs are forced to move randomly on land in an effort to find water. This finding supports the observations of Goodyear, '70), who found that Fundulus notti were able to navigate towards the water when the sun was shining, yet they were unable to do so under overcast skies (Goodyear, '70). Taken together, these studies suggest that light levels have a strong impact on the ability of Fundulus spp. to navigate overland.

When the water in the sea table was covered with reflective aluminum foil, mummichogs moved towards the foil more often than toward the other ends of the platform. There was no significant difference between fish behavior in light versus foil treatments, thus foil appears to be an adequate analog for the sensory input from the water to the fish. This finding suggests that mummichogs navigate by moving toward the reflection of light off the surface of water. Navigation by reflection has not been previously described for other fishes on land, but it has been described in insects, which use strong horizontal polarizations of light reflected off the surface of water to navigate (Szentkirályi et al., 2003). Fishes are able to discern the polarization of light underwater (Hawryshyn, '92), so it is possible that mummichogs use the polarization of light off the surface of water as a stimulus for navigation. However, while light can be polarized by the surface of water, light is not polarized when reflected by metal. Because the foil used in this study should not polarize light, mummichogs do not appear to rely on polarized light reflected off the surface of water, but rather use the reflection of light waves in general. 
Although vision is considered to be an important means of gathering sensory information on land in fishes that make terrestrial excursions (Sayer, 2005; Gibb et al., 2013), this is the first study to investigate the role of specific visual stimuli in fish terrestrial navigation. Our results indicate that reflections of light off the surface of the water are an important visual cue for $F$. heteroclitus, as it locates a body of water. This visual stimulus is likely prominent due to a lack of ability of the eyes of fishes to form a focused image on land. Because of the similarity in refractive indices between water and the vertebrate cornea, the cornea contributes little refraction to light entering the eyes from water, and most fishes instead rely on spherical lenses to refract light to form a focused image. When a fish moves on land, the now-exposed cornea will increase the refraction of light, and the spherical lens will produce an image on the retina that is out of focus, likely limiting the ability of fishes to visually resolve the details of their habitats (Boumis et al., 2014). Some fishes have adaptations for vision in air, including modifications to reduce the refraction of light by the cornea (e.g., Mnierpes macrocephalus and Alticus kirkii; Graham and Rosenblatt, '70; Sayer, 2005) or by the lens (e.g., Periopthalmus spp.; Sayer, 2005). Highly specialized fishes can produce an image in air and underwater simultaneously, such as Anableps anableps (Swamynathan et al., 2003). Fishes without such adaptations, such as Fundulus heteroclitus, however, are unlikely to be able to form a focused image in air and may instead rely on simple visual cues, such as reflections of light off the water.

Because mummichogs begin and end a tail-flip jump from their lateral aspect, the uprighting behavior is not necessary to perform consecutive jumps-rather it appears to be a behavior that allows mummichogs to visually survey their environment. Terrestrial specialists, such as mudskippers (Periopthalmus spp.) and amphibious blennies (e.g., Alticus arnoldorum), which are socalled prone jumpers, have been hypothesized to survey their surroundings before jumping (Gibb et al., 2013). The combination of tail-flip jumps and the uprighting behavior of mummichogs may be a less-derived, yet analogous behavior to prone jumping. Mummichogs perform a tail-flip jump to initiate terrestrial movement and land on their lateral aspect. Before they jump again, they upright and wriggle to reposition their bodies and change directions. Wriggles in mummichogs appear to be kinematically similar to the "squiggles" of the mangrove rivulus, Kryptolebias marmoratus (Pronko et al., 2013). K. marmoratus is a quasi-amphibious fish, known to spend weeks on land at a time, moving around using tail-flip jumps and other locomotor behaviors. However, while squiggle behaviors in K. marmoratus are cyclic and allow a fish to displace itself overland, mummichogs appear to perform brief wriggles to reorient their bodies and rely on tail-flip jumps to move longer distances.

Because the bodies of mummichogs are less elongate than mudskippers, blennies, or other prone jumpers, they may be unable to produce a jump from a prone, upright position. An uprighting behavior has also been described for K. marmoratus (Gibb et al., 2013), which spend very long periods of time on land. However, whereas mummichogs generally keep their tails upright, K. marmoratus lie with their posterior body twisted $90^{\circ}$, so that their caudal peduncle remains in contact with the substrate. The twist in the mangrove rivulus' tail allows it to transition into a jump more quickly than if its tail was held at $90^{\circ}$ to the substrate (Gibb et al., 2013). While mummichogs spend less time on land than the mangrove rivulus, the presence of an uprighting behavior supports the hypothesis that a prone position is adopted as increased terrestriality evolves. For mummichogs, mangrove rivulus, and possibly many other species of small fish that live at the water's edge, the uprighting behavior may allow the fish to gather critical visual information about its environment before it initiates the next jump. The presence of such behaviors among disparate groups of amphibious fishes and the evidence presented here documenting the importance of visual cues for F. heteroclitus support the evolutionary hypothesis that a prone body position evolves as fish move onto land because vision is a critical sensory system for navigation in terrestrial habitats.

\section{ACKNOWLEDGMENTS}

We thank Dr. Frank E. Fish and the Anatomy and Function of Marine Vertebrates 2013 cohort at Shoals Marine Laboratory for their intellectual and practical assistance. We also thank Dr. William E. Bemis for his support and mentorship of Noah Bressman throughout his high school and undergraduate research endeavors. We are also grateful to the Shoals Marine Laboratory for providing laboratory space, equipment, and assistance. Funding for this work was provided by the Andrew W. Mellon Foundation through Cornell University to Noah Bressman and by the National Science Foundation (DEB-1310812) to Stacy Farina.

\section{LITERATURE CITED}

Agresti A. 2002. Categorical data analysis. Hoboken, NJ: John Wiley and Sons, Inc. p 701.

Aronson LR. 1971. Further studies on orientation and jumping behavior in the gobiid fish, Bathygobius soporator. Ann N Y Acad Sci 188:378-392.

Boumis RJ, Ferry LA, Pace CM, Gibb AC. 2014. Heads or tails: do stranded fish (mosquitofish, Gambusia affinis) know where they are on a slope and how to return to the water? PLOS ONE 9(8):e104569.

Coombs S, Montgomery JC. 1999. The enigmatic lateral line system. In: Fay RR, Popper AN, editors. Comparative Hearing: fish and amphibians. New York, NY: Springer. p 319-362.

Gervais MR, Tufts BL. 1998. Evidence for membrane-bound carbonic anhydrase in the air bladder of Bowfin (Amia calva), a primitive airbreathing fish. J Exp Biol 201:2205-2212.

Gibb AC, Ashley-Ross MA, Hsieh ST. 2013. Thrash, flip, or jump: the behavioral and functional continuum of terrestrial locomotion in teleost fishes. Integr Comp Biol 53:295-306. 
Gibb AC, Ashley-Ross MA, Pace CM, Long JH, Jr. 2011. Fish out of water: terrestrial jumping by fully aquatic fishes. J Exp Zool 313:1-5.

Goodyear CP. 1970. Terrestrial and aquatic orientation in the starhead topminnow, Fundulus notti. Science 168:603-605.

Graham JB, Rosenblatt RH. 1970. Aerial vision: unique adaptation in an intertidal fish. Science 168:586-588.

Halpin PM, Martin KLM. 1999. Aerial respiration in the salt marsh fish Fundulus heteroclitus (Fundulidae). Copeia 1999:743-748.

Hara TJ. 1975. Olfaction in fish. Prog Neurobiol 5:271-335.

Harris GG, van Bergeijk WA. 1962. Evidence that lateral-line organ responds to near-field displacements of sound sources in water. J Acoust Soc Am 34:1831-1841.

Hawryshyn CW. 1992. Polarization vision in fish. Am Scientist 80:164-175

Hsieh ST. 2010. A locomotor innovation enables water-land transition in a marine fish. PLoS ONE 5(6):e11197.

Hughes GM, Singh BN. 1970. Respiration in an air-breathing fish, the climbing perch Anabas testudineus bloch: oxygen uptake and carbon dioxide release into air and water. J Exp Biol 53:265-280.

King HM, Shubin NH, Coates MI, Hale ME. 2011. Behavioral evidence for the evolution of walking and bounding before terrestriality in sarcopterygian fishes. Proc Natl Acad Sci USA 1-6.

Lund U, Agostinelli C. 2012. CircStats: Circular Statistics, from "Topics in circular Statistics" (2001). R package version 0. 2-4.http://CRAN. R-project.org/package $=$ CircStats

Martin KLM, Bridges CR. 1999. Respiration in water and air. In: Horn $\mathrm{MH}$, Martin KLM, Chotkowski MA, editors. Intertidal fishes: life in two worlds. San Diego, CA: Academic Press. p 54-78.

Mast S0. 1915. The behavior of Fundulus, with special reference to overland escape from tide pools and locomotion on land. J Anim Behav 5:341-350.
Ong KJ, Stevens ED, Wright PA. 2007. Gill morphology of the mangrove killifish (Kryptolebias marmoratus) is plastic and changes in response to terrestrial air exposure. J Exp Biol 210: 1109-1115.

Pronko AJ, Perlman BM, Ashley-Ross MA. 2013. Launches, squiggles, and pounces, oh my! The water-land transition in mangrove rivulus (Kryptolebias marmoratus). J Exp Biol 216: 3988-3995.

R Core Team. 2013. R: A language and environment for statistical computing. Vienna: R Foundation for Statistical Computing. ISBN 3-900051-07-0. http://www.R-project.org/

Sayer MDJ. 2005. Adaptions of amphibious fish for surviving life out of water. Fish Fish 6:186-211.

Schneider CA, Rasband WS, Eliceiri KW. 2012. NIH Image to ImageJ: 25 years of image analysis. Nat Methods 9:671-675.

Swanson B0, Gibb AC. 2004. Kinematics of aquatic and terrestrial escape responses in mudskippers. J Exp Biol 207: 4037-4044.

Swamynathan SK, Crawford MA, Robison WG, Jr, Kanungo J, Piatigorsky J. 2003. Adaptive differences in the structure and macromolecular compositions of the air and water corneas of the "four-eyed" fish. FASEB J 17:1996-2005.

Szentkirályi F, Bernáth B, Kádár F, Retezár I. 2003. Flight of ground beetles towards polarized and unpolarized light sources. European Carabidology Proceedings of the 11th European Carabidologist Meeting, DIAS Report 114:313-324.

Taylor DS, Turner BJ, Davis WP and, Chapman BB. 2008. Natural history note: a novel terrestrial fish habitat inside emergent logs. Am Naturalist 171:263-266.

Webb JF, Montgomery JC, Mogdans J. 2008. Bioacoustics and the lateral line system of fishes. In: Webb JF, Fay RR, Popper AN, editors. Fish Bioacoustics. New York, NY: Springer. p 145-182. 